\title{
Expert System based on RPW Technique to Evaluating Multi Product Assembly Line Balancing Solution
}

\author{
Ashish Manoria \\ Reader in Deptt. of M.E \\ S.A.T.I, Vidisha (M.P.)
}

\author{
Sandip Kumar Mishra \\ M.Tech Scholar in M.E \\ S.A.T.I, Vidisha (M.P.)
}

\author{
Sachin Maheshwar \\ M.Tech Scholar in M.E \\ S.A.T.I, Vidisha (M.P.)
}

\begin{abstract}
The traditional assembly line balancing problem considers the manufacturing process of a product where production is specified in terms of a sequence of tasks that need to be assigned to workstations. Each task takes a known number of time units to complete. Also, precedence constraints exist among tasks: each task can be assigned to a station only after all its predecessors have been assigned to stations. The assembly line balancing problem arises and has to be solved when an assembly line has to be configured or redesigned. It consists of distributing the total work load for manufacturing any unit of the product to be assembled among the workstations along the line.

In this paper Rank positional weight method for Type I of the Simple Assembly Line Balancing Problem (SALB P) and multi product assembly line balancing problem (MALBP) for the hybrid system are described. Type I of SALBP (SALBP1) and MALBP consist of assigning tasks to work stations such that the number of stations is minimized for a given production rate and cycle time. In this paper, the problem is motivated by a vehicle-sequencing problem at a North India Automobile truck assembly plant.
\end{abstract}

The programmed is coded in C\# (C sharp). In this problem, precedence constraints between the tasks have to be considered.

\section{Keywords}

Assembly line balancing, RPW Heuristic Method, Expert System.

\section{INTRODUCTION}

Nowadays companies around the world are producing high quality products to sell them at the lowest price possible. This is not because they don't want to earn more money through the sale of products. It is because they are facing the necessity of increasing their participation in the market because competitors also are selling products with high quality at the lowest price possible. There are several techniques to continuously improve quality and reduce operation costs. One of these techniques is called Line Balancing. The line balancing problem consists of assigning approximately the same amount of workload to each workstation (worker) in an assembly line. Line balancing involves selecting the appropriate combination work task to be performed at each work station so that the work is performed in a feasible sequence and approximately equal amounts of time are required at each of the work stations. An assembly line is a flow-oriented production system where the productivity units performing the operations, referred to as stations, are aligned in a serial manner. The work pieces visit stations successively as they are moved along the line usually by some kind of transportation system, e.g. a conveyor belt [1]-[2].

Originally, assembly lines were developed for a cost efficient mass-production of standardized products, designed to exploit a high specialization of labour and the associated learning effects [3].Since the times of Henry Ford and the famous model-T, however ,product requirements and thereby the requirements of production system have changed dramatically [4]. In order to respond to diversified customer needs, companies have to allow for an individualization of their products. For example, a car manufacturer can offer a catalogue of optional features which, theoretically, results in different models. Multipurpose machines with automated tool swaps allow for facultative production sequences of varying models at negligible setup costs. This makes efficient flow-line systems available for low volume assembly to order production and assists modern production strategies like mass-customization, which in turn ensures that the thorough planning and implementation of assembly systems will remain of high practical relevance in the foreseeable future [5].Due to high level of automation, assembly systems are associated with considerable investment costs. Therefore, the configuration of an assembly line is of critical importance for implementing a cost efficient production system. Configuration planning generally comprises all tasks and decisions which are related to equipping and aligning the productive units for a given production process, before the actual assembly process can start. This includes setting the system capacity (cycle time, number of stations, station equipment) as well as assigning the work content to productive units (task assignment, sequence of operations) [6] - [8].

In light of the high practical relevance, it is not surprising that a massive body of academic literature covers configuration planning of assembly systems. The apparent lack of more recent scientific studies on the application of ALB-algorithms indicates that there is a wide gap between the academic discussion and practical applications. Three theoretical reasons might explain the abovementioned deficit: (i) Researchers have not considered the "true" real-world problems so far. (ii) The problems were covered, but could not be solved to satisfaction. (iii) Scientific results could not be transferred back to practical applications, e.g. because solutions for special case studies could not be extended to general problems. Any of these reasons might result from a fundamental problem in communication, which is expressed by an inconsistent use of terms and definitions for the various types of balancing problems [9]. This is not only inhibiting the communication within the research community, but also the knowledge transfer to practice. 
A first, yet decisive step to resolve this problem lies in a consistent, authoritative classification of assembly line balancing problems including all appropriate constraints and objective. A uniform classification enables practitioners to compare their individual problem setting with those covered by research challenges can be identified by configuring the exiting body of literature according to the classification scheme.

Due to very different conditions in industrial manufacturing, assembly line production systems and corresponding ALB problems show a great diversity. In the following characterize the relevant properties of assembly lines which have to be considered when balancing those lines [10]. Number and variety of products: if only one product or several products with almost identical production processes are assembled, the production system can be treated as a single -model line. In modern production systems, however, several products or different model of the same base product often share the same assembly line. In general, two different forms of organization are distinguished: A mixed-model line for producing the units of different models in an arbitrarily intermixed sequence. The sequence is important with respect to the efficiency of a line, because the task time may differ considerably between models. Therefore, the mixed-model ALB problem is connected to a sequencing problem which has to find a sequence of models to be produced such that inefficiencies like utility work, line stoppage, and off-line repair are minimized. However, the balancing and the sequencing problem usually cannot be solved simultaneously, because the sequence depends on the sort-term model-mix which is typically not known at the time when the line has to be balanced. Instead, the balancing problem is often based on an average model-mix. In order to expect the later sequencing problem adequately, a horizontal balancing objective is usually utilized which attempts to equalize the work content of stations over all models.

A multi-model line produces a sequence of batches with intermediate setup operations. Therefore, the ALB problem is not only connected to sequencing but also to a lot sizing problem. However, both additional problems are typically not part of the long or medium-term configuration decisions [11].

In a U-shaped assembly line the stations are arranged along a rather narrow "U", where both legs are closely together. Stations in between those legs may work at two segments of the line facing each other simultaneously. This means that work pieces can revisit the same station at a stage in the production process without changing the flow direction of the line. This can result in a better of station loads due to the larger number of task station combinations. Instead of a single $\mathrm{U}$, the line can also be organized as a sequence of several $\mathrm{U}$ shaped line segments, called $n-U$ line [11]-[12].

The Assembly Line Balancing Problem (ALBP) can be divided into two groups, according to the classification proposed by Baybars [13] .The objective is to minimize require labour input and facility investments for a given amount of output. An assembly line exists when we assemble or handle any device or product in a planned, sequential manner with two or more operators performing tasks of repetitive work at established workstations. When the product has many operations and the demand is high, the process of balancing the line becomes more and more difficult. According to Ajenblit (1998) there are two types of optimization problems for the line balancing problem (LBP). "In the Type I problem [14], the cycle- time (maximum amount of time units that can be spent at each work station) is fixed and the objective is to minimize the required number of work stations. The Type II attempts to minimize the maximum cycle-time given a fixed number of work stations. The assembly line balancing problem can be explained as to assign the tasks according to the precedence relations and some other constraints to each workstation for maximum efficiency possible, and thereby achieving the maximum productivity. The line balancing problem (LBP) assigns task to workstations satisfying two requirements. First time required to complete the task assigned to a work station must not exceed the cycle time (rate at which the parts must be produced) and the precedence relationships must be satisfied. The cycle time, precedence diagram and task time is the information needed to apply in the LBP.

In the present work we had taken the objective to reduce the number of workstations or to find out the optimum number of stations and develop the expert system for this, a heuristic RPW method is used. The objective is to assign operations to workstations in order to balance the workload and minimise manpower requirements when more than one product variant has to be assembled in a line. Since assembly process and process times may not be the same for different products, a single line cannot be perfectly balanced for each of the products.

\section{HEURISTIC RPW RULE TO SOLVE THE SALBP AND MALBP}

The heuristic means to discover. That is this method is based on the logic and the past experience rather than mathematical proof. The six popular heuristic algorithms, namely, Ranked Positional Weight, Kilbridge and Wester, Moodie and Young, Hoffmann precedence matrix, immediate update first fit ,and rank and assign heuristic methods. All these are having advantages and disadvantages over each other .But the most popular between them is the Rank positional weight system.

The step by step procedure of RPW method is given below:

1. Draw the precedence diagram.

2. For each work element, determine the positional weight. It is the total time on the longest path from the beginning of the operation to the last operation of the network.

3. Rank the work elements in descending order of ranked positional weight (RPW).

4. Assign the work element to a station. Choose the highest RPW element. Then, select the next one. Continue till cycle time is not violated. Follow the precedence constraints also.

5. Repeat step 4 till all operations are allotted to the workstations.

\subsection{Constraints in line balancing problem}

- We should know precedence relationship for each operation.

- Divide the tasks into maximum number of activities possible.

- The number of workstations should not be more than total number of task i.e. Restriction on number of workstation should be there.

- Station time individually should not be more than cycle time. 
- No operation should be greater than the cycle time.

- If any operation found more than cycle time sort it and check it by apply number of workers on it to have within cycle time or separate the operation if possible.

\section{EXPERT SYSTEM}

The old method of balancing the line manually has been changed by using an expert system . The expert system is a programming language having being used the applications of Heuristic for the better results. This system will give us the results for mixed model, multi product assembly line balancing. The system is developed by using the $\mathrm{C}$ sharp programming. The developed system can be used for any number of tasks which are to be performed on the products.

\subsection{Assumptions of Expert System}

1. A task cannot split in two or more stations.

2. It should not break precedence given.

3. Cycle time is given and should be greater than the maximum task time required for any operation.

4. All task must be processed and on given station only.

\subsection{Algorithm for Expert system}

a) Establish station and assign the maximum positional weight to it.

Condition statement: if - for unassigned task $(\mathrm{T} 1, \mathrm{~T} 2, \ldots \ldots \ldots, \mathrm{Tn}) \mathrm{The}$ task with maximum RPW will be taken first and will be assigned.

b) Condition for assigning the maximum possible tasks to a station.

IF Stij = 0AND St_Time $<=$ Tc AND J $<=$ Tmax It will assign the task to the station.

c) Condition to check the tie in positional weights. IF RPWij = RPWi+1j; THEN select task having longer time duration.

d) Check to have assigned the task to next workstation. IF St_Time>Tc assign task to next station.

e) Forming the loop till the last task assigned IF task $\mathrm{ij}<=0$ stop the program.

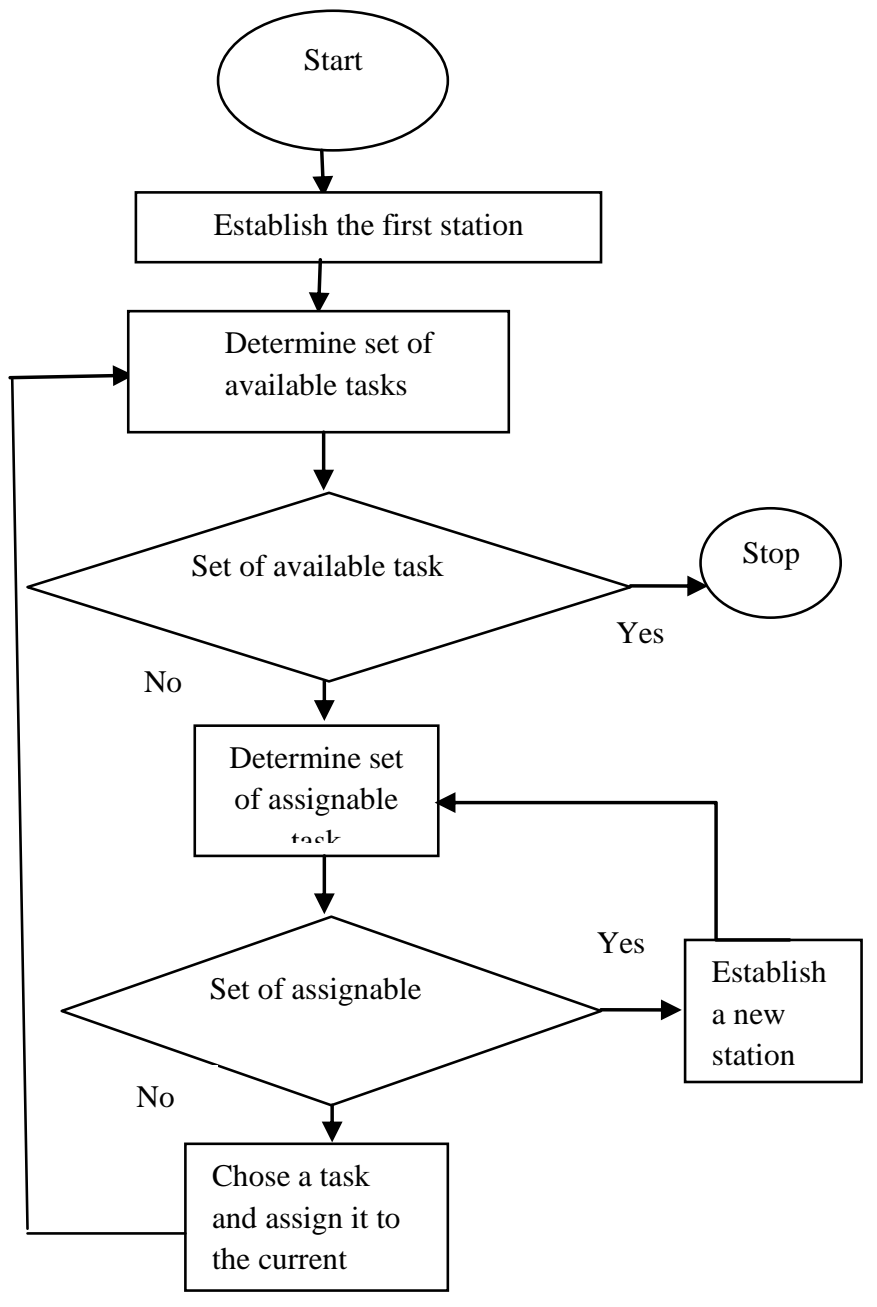

Fig 1: Flow chart of the program

\section{AN INDUSTRIAL APPLICATION}

Let us consider an assembly problem from the automotive industry. A manufacturer wishes to assemble two models of commercial vehicles on the same assembly line. The two models have most of their parts in common, the cycle time available for each model (product) is about 5minutes, it is the average maximum time that can be used to assemble a unit of product at each stations. Table I describes the tasks and gives the operation times for each of the 15 assembly tasks. Table II shows the calculation of RPW of each task. For this application the resources are manual, hard automated robotized. The models are quite similar, requiring nearly the same amount of time to be assembled. 
Table 1. Data from assembly section of an $\mathrm{ABC}$ industry

\begin{tabular}{|c|c|c|c|}
\hline Task No. & Task & Activity Description & $\begin{array}{c}\text { Task Time } \\
\text { (Min) }\end{array}$ \\
\hline 2 & $\mathrm{~b}$ & longitudinal assembly & 3.00 \\
\hline 1 & a & spot projection welding & 2.00 \\
\hline 3 & $\mathrm{c}$ & floor channel station & 5.00 \\
\hline 4 & $\mathrm{~d}$ & floor panel & 5.00 \\
\hline 5 & $\mathrm{e}$ & mig welding & 4.00 \\
\hline 7 & $\mathrm{~g}$ & sit mounting & 3.00 \\
\hline 6 & $\mathrm{f}$ & bulk head panel & 5.00 \\
\hline 8 & $\mathrm{~h}$ & final assembly & 4.00 \\
\hline 11 & K & loose parts & 2.00 \\
\hline 12 & $\mathrm{~L}$ & indicator LH \& RH & 3.00 \\
\hline 9 & I & head light assembly & 4.00 \\
\hline 13 & M & break paddle & 3.00 \\
\hline 10 & $\mathrm{~J}$ & paint shop & 5.00 \\
\hline 14 & $\mathrm{~N}$ & cluster, wiper motor & 4.00 \\
\hline 15 & o & steering, chain assembly & 2.00 \\
\hline
\end{tabular}

Table 2. Computational results with a cycle time 5 minutes

\begin{tabular}{|c|c|c|c|c|c|c|}
\hline $\begin{array}{c}\text { Task } \\
\text { No }\end{array}$ & Task & $\begin{array}{c}\text { Activity } \\
\text { Description }\end{array}$ & $\begin{array}{c}\text { Task } \\
\text { Time } \\
\text { (Min) }\end{array}$ & RPW & $\begin{array}{c}\text { Ranked } \\
\text { PW }\end{array}$ & Station \\
\hline 2 & B & $\begin{array}{l}\text { longitudinal } \\
\text { assembly }\end{array}$ & 3.00 & 33.00 & 1 & 1 \\
\hline 1 & A & $\begin{array}{l}\text { spot projection } \\
\text { welding }\end{array}$ & 2.00 & 32.00 & 2 & 1 \\
\hline 3 & $\mathrm{C}$ & $\begin{array}{c}\text { floor channel } \\
\text { station }\end{array}$ & 5.00 & 30.00 & 3 & 2 \\
\hline 4 & $\mathrm{D}$ & floor panel & 5.00 & 25.00 & 4 & 3 \\
\hline 5 & $\mathrm{E}$ & mig welding & 4.00 & 20.00 & 5 & 4 \\
\hline 7 & G & sit mounting & 3.00 & 18.00 & 6 & 5 \\
\hline 6 & $\mathrm{~F}$ & $\begin{array}{c}\text { bulk head } \\
\text { panel }\end{array}$ & 5.00 & 16.00 & 7 & 6 \\
\hline 8 & $\mathrm{H}$ & final assembly & 4.00 & 15.00 & 8 & 7 \\
\hline 11 & K & loose parts & 2.00 & 14.00 & 9 & 8 \\
\hline 12 & $\mathrm{~L}$ & $\begin{array}{c}\text { indicator LH \& } \\
\text { RH }\end{array}$ & 3.00 & 12.00 & 10 & 8 \\
\hline 9 & I & $\begin{array}{l}\text { head light } \\
\text { assembly }\end{array}$ & 4.00 & 11.00 & 11 & 9 \\
\hline 13 & M & break paddle & 3.00 & 9.00 & 12 & 10 \\
\hline 10 & $\mathrm{~J}$ & paint shop & 5.00 & 7.00 & 13 & 11 \\
\hline 14 & $\mathrm{~N}$ & $\begin{array}{l}\text { cluster, wiper } \\
\text { motor }\end{array}$ & 4.00 & 6.00 & 14 & 12 \\
\hline 15 & $\mathrm{O}$ & $\begin{array}{l}\text { steering, chain } \\
\text { assembly }\end{array}$ & 2.00 & 2.00 & 15 & 13 \\
\hline
\end{tabular}




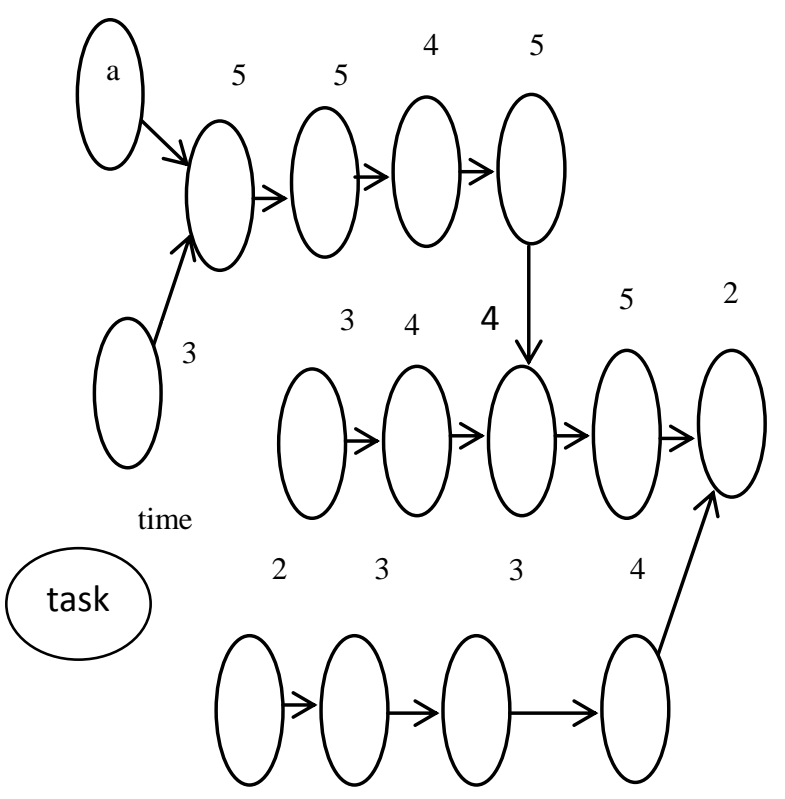

Fig 1: Precedence Diagram of the tasks

Table 3. Computational results with a cycle time 5 minutes

\begin{tabular}{|c|c|c|}
\hline Sr. No. & Description & Expert System \\
\hline 1 & Cycle time & 5 minutes \\
\hline 2 & Efficiency & $83 \%$ \\
\hline 3 & No. of work station & 13 \\
\hline 4 & No. of operations & 15 \\
\hline
\end{tabular}

Table 4. Comparison of result

\begin{tabular}{|c|c|c|}
\hline Description & Present & $\begin{array}{c}\text { By expert } \\
\text { system }\end{array}$ \\
\hline No. of stations & 15 & 13 \\
\hline Line efficiency & $70 \%$ & $83 \%$ \\
\hline Cycle Time & $5 \mathrm{~min}$. & $5 \mathrm{~min}$. \\
\hline
\end{tabular}

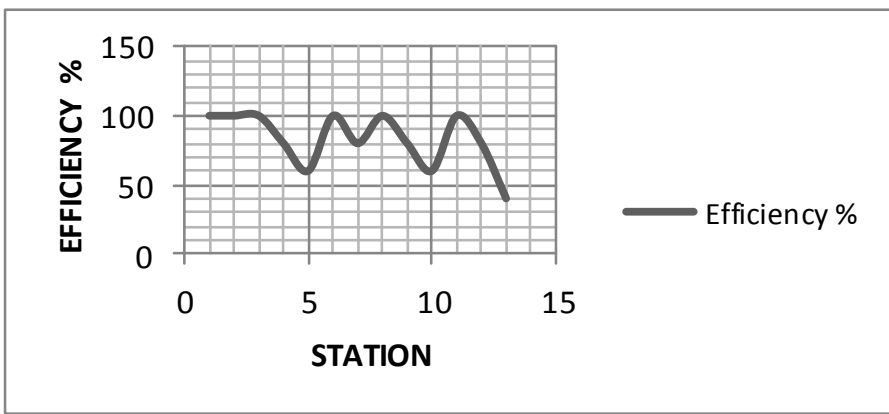

Fig 2. Variation of efficiency at each station

\section{CONCLUSION}

The result showed that rank positional weight heuristic rule can produce good solutions for the straight line LBP. It was shown that the addition of an expert algorithm can improve the current solution. This study has taken a step in the direction of finding good result for the SALBP and MALBP. The major role of this study is to look these problems and introducing the expert system accordingly to minimize slack time at each work station and get task in shorter period of time. The expert system showed that the expert system had a good potential to solve the current industrial problem of assembly line balancing for multi products to have an optimum utilization of the resources.

\section{REFERENCES}

[1] Kusiak A (2000) Computational intelligence in design and manufacturing. Wiley, New York

[2] Daudin, M (2002). Lean assembly: The nuts and bolts of making assembly operations flow. Productivity, New York.

[3] Evans, J.R, (1983), Applied production and Operations Management, West Publishing, New York, 301-330 Jersey, 419-424.

[4] Boysen, N.Fliedner, M., 2006. A versatile algorithm for assembly line balancing. Working paper, University of Hamburg, German.

[5] Bukchin, J., Masin, m., 2004. Multi-objective design of team oriented assembly systems. European journal of Operational Research 156,326-352.

[6] Bukchin , Y., Meller, R.D., 2005. A space allocation algorithm for assembly line components. IIE Transactions 37,51-61.

[7] Amen M., "Cost-oriented assembly line balancing:Model formulations, solution difficulty, upper and lower bounds." European journal of Operational Research 168, 2006, pp 747-770.

[8] Kilbridge Maurice D. and wester L. Operations research, vol. 10, No.5 (sep-oct., 1962), pp. 626-638.

[9] Moodie, C. L., and H.H Young. (1965). "A Heuristic Method of Assembly Line Balancing for Assumptions of Constant or Variable Work Element Times". Industrial Engineering 16, 23-29.

[10] Aase G.R., Olson J.R., Schniederjans M.J.,’U-shaped assembly line layouts and their impact on labour productivity: An Experimental study." European Journal of Operational Research, 156, 2004, pp 698-711.

[11] Baykasoglu, A ., Ozbakir, L., 2006. Stochastic U-line balancing using genetic algorithms. International journal of Advanced Manufacturing technology, doi: 10.1007/s0017-005-0322-4.

[12] Baybars, I. (1986): "A survey of exact algorithms for the simple assembly line balancing problem". Management Science, Vol. 32, No. 8, pp. 909-932.

[13] Boctor, F.F. (1995): "A Multiple-rule Heuristic for Assembly Line Balancing". Journal of the Operational Research Society, 46, pp. 62-69.

[14] Boctor, F.F. (1995): "A Multiple-rule Heuristic for Assembly Line Balancing". Journal of the Operational Research Society, 46, pp. 62-69. 
[15] Amen, M.'Heuristic methods for cost-oriented assembly line balancing: A comparison on solution quality and computing time". Int. Journal of production economics, vol. 69,225-264, 2001

[16] Scholl A, Christian B (2006) State-of-the-art exact and heuristic solution procedures for simple assembly line balancing. Eur J Oper Res 168(3):666-693 .

[17] Dar-El, E. M., "Solving Large Single-model Assembly Line Balancing Problem - A comparative Study", AIIE Transactions, Vol. 7, No 3, (1975), pp. 302-306.

[18] Becker C,scholl A (2006) A survey on problems and methods in generalised assembly line balancing .Eur. J Oper Res 168:694-715.
[19] Baudin,M.(2002).Lean assembly :The nuts and bolts of making assembly operations flow.productivity,New York.

[20] Tonge, Fred M, "Summary of a Heuristic Line Balancing Procedure", Management Science,, v 7, n 1 (1960),pp2142.

[21] Jackson J.R., "A Computing Procedure for a Line Balancing Problem”, Management Sci., v 2, n 3, (1956), pp 261-272.

[22] St.T. Hackman, H.J. Magazine, T.S. Wee, Fast, effective algorithms for simple assembly line balancing problems, Operations Research 37 (1989) 916\}924.

[23] N.R. Reeve, W.H. Thomas, Balancing stochastic assembly lines, AIIE [American Institute of Industrial Engineers] Transactions 5 (1973) 223$\} 229$. 